\title{
Üriner sistem taşı olan hastalarda tam idrar analizi idrar kültürü ile uyumlu mu?
}

Is there a correlation between urine culture and urine analysis for patients with urinary stones?

\author{
Türk H İşoğlu CS Yoldaş M Karabıçak M Ekin R G Zorlu F
}

İzmir Tepecik Eğitim Araştırma Hastanesi, Üroloji Kliniği, İzmir, Türkiye

\section{Özet}

Amaç: Böbrek ve/veya üreter taşı olan hastalarda tam idrar analizinin idrar kültürü sonucu ile karşılaştırılması ve güvenilirliğinin değerlendirilmesini amaçlandı.

Gereç ve Yöntem: Ocak 2011-Ocak 2013 tarihleri arasında başvuran semptomatik idrar yolları enfeksiyonu (IYE) ön tanısı ile üreter ve/veya böbrek taşı olup tam idrar tetkiki (TiT), idrar mikroskopisi ve idrar kültürü istenen 300 hasta (Grup 1) çalışmaya alındı. Kontrol grubu olarak (Grup 2) aynı tarihler arasında semptomatik IYE ön tanısı ile kliniğimize başvuran TiT, idrar mikroskopisi ve idrar kültürü olan 300 hasta incelendi. Her 3 tetkiki olmayan hastalar çalışma dışı bırakıldı. Sonuçlar ki-kare test ve student t-test SPSS v.19.0 kullanılarak değerlendirildi. 0.05 'ten küçük $p$ değeri istatistiksel olarak anlamlı kabul edildi.

Bulgular: Hastaların 68 (\%11.3)'inde idrar kültüründe üreme oldu, en çok üreyen bakteri E. coli (\%77.9) olarak görüldü. Taş olan hastaların 29 (\%9.9)'unda, taş olmayan hastaların ise 39 (\%13)'unda idrar kültüründe üreme oldu. Grup 1'de nitrit, lökosit, eritrosit ve mikroskopide bakteri görülmesinin negatif prediktif değerleri sırasıyla \%93, \%96, $\% 96, \% 90$ olarak bulundu. Grup 2 de ise nitrit, lokösit, eritrosit, mikroskopide bakteri görülmesinin negatif prediktif değerleri sırasıyla \%88.8, \%93.3, \%93.2, \%87.1 olarak bulundu.

Sonuç: Kliniği IYE ile uyumlu hastalar için bakteriüri, piyüri, hematüri ve nitrit testleri tek başlarına tanı koymak için yeterli olmayıp özellikle komplike IYE düşünülen hastalar kültür sonuçları ile birlikte değerlendirilmelidir. Üriner sistem taşı olan hastalarda da bu tetkikler aynı şekilde kullanılabilir. Ancak bu hasta grubu komplike IYE sınıfında değerlendirildiği için mutlaka idrar kültürü yapılmalıdır.

Anahtar Sözcükler: İdrar yolu enfeksiyonu, üriner sistem taşı.

\section{Summary}

Aim: The aim of the study is compare the reliability and efficacy of full urine tests and urine cultures in kidney and/or ureter stone patients.

Materials and Methods: Between January 2011- January 2013, 471 patients who were admitted to our clinic with symptomatic ureter and/or kidney stones were evaluated (Group 1). These patients had a full urine test, urine microscopy and urine culture. The control group (Group 2),consisted the patients who admitted with symptomatic urinary tract infection (UTI) in the same period. The patients who did not have all three diagnostic tests were excluded. Results were evaluated with chi-square and student's t test by SPSS v.19.0. $p<0.05$ is considered as statistically significant.

Results: Sixty-eight (11.3\%) patients had a positive urine culture. E.coli (77.9\%) is the mostly isolated bacteria. Twenty-nine (9.9\%) of stone patients and 39 (\%13) of non-stone patients had a positive urine culture. For Group 1 , negative predictive values of nitrite, leucocyte, erytrocyte and bacteria seen in microscopy were 93\%, 96\%, 96\% and $90 \%$, respectively. For Group 2, negative predictive values of nitrite, leucocyte, erytrocyte and bacteria seen in microscopy are $88.8 \%, 93.3 \%, 93.2 \%$ and $87.1 \%$, respectively.

Conclusion: Full urine tests (pyuria, hematuria, bacteriuria, nitrite tests), are not enough to diagnose urinary tract infection, especially for complicated UTI. These tests should be correlated with urine cultures. Full urine tests can also be used in uinary stone patients safely. However, urinary stone patients with UTI can also be categorized as complicated UTI, and all shoud be evaluated by urine culture.

Key Words: Urinary tract infection, urinary tract stone.

\footnotetext{
Yazışma Adresi: Hakan TÜRK

İzmir Tepecik Eğitim ve Araştırma Hastanesi, Üroloji Kliniği,

İzmir, Türkiye

Makalenin Geliş Tarihi: 07.04.2014 Kabul Tarihi: 25.06.2014
} 


\section{Giriş}

İdrar yolu enfeksiyonları (IYE) asemptomatik sistitten septik şoka kadar gidebilen ve çoğunlukla bakterilerin sebep olduğu, toplumda yaygın olarak görülen enfeksiyonlardır $(1,2)$. Bu enfeksiyonlar üst ve alt üriner sistem enfeksiyonları olmak üzere iki grupta incelenmektedir. Mesane ve üretranın etkilenmesi alt üriner sistem enfeksiyonu; üreter, pelvis ve böbreklerin etkilenmesi ise üst üriner sistem enfeksiyonu olarak adlandırılmaktadır. Ayrıca bu enfeksiyonlar, komplike enfeksiyonlar(altta yatan bir üriner sistem anomalisi, geçirilmiş cerrahi, taş veya üriner sistem tümörü gibi sistemik hastalık varlığında) ve komplike olmayan enfeksiyonlar (altta yatan bir hastalık veya anomali olmayan) olarak iki başlık halinde incelenmektedir $(3,4)$.

IYE'nin genel toplumda en sık görülen bakteriyel enfeksiyon olduğu belirtilmektedir (4). Amerika'da IYE nedeniyle yılda 7 milyon poliklinik, 1 milyon acil servis başvurusu bildirilmiş ve bunların 100 bini hastaneye yatışla sonuçlanmıştır (5). Bu oranlar göz önüne alındığında IYE tanısı, IYE'nin önlenmesi ve tedavisi büyük önem kazanmaktadır. Ekonomik boyut değerlendirildiğinde ise bu durum daha da önemli hale gelmektedir $(5,6)$.

IYE semptomlarının olması, tanı koymada etkili olabilmekte ancak her zaman gerçek enfeksiyon varlığını göstermemektedir $(3,7,8)$. IYE semptomları içinde ateş, pollaküri, ani sıkışma hissi, dizüri, idrar akımında yavaşlama, noktüri, suprapubik veya yan ağrısı sayılabilir (9). Bununla birlikte tüm bu semptomlar enfeksiyon dışı bazı durumlarda da ortaya çıkabilmektedir. Bu nedenle laboratuvar tetkikleri ile tanı desteklenmelidir. Laboratuvar bulguları ise piyüri, bakteriüri, lökosit esteraz pozitifliği, nitrit pozitifliği ve idrar kültüründe patojen bakteri üremesidir $(10,11)$. IYE toplumda çok sık görüldüğünden, ciddi işgücü kaybına ve hayat kalitesinin bozulmasına neden olduğundan dolayı hastalığın etkili ve hızı tedavisi önem arz etmektedir. Yapılan çalışmalarda idrar analizi ile tespit edilen piyüri, proteinüri, nitrit ve lökosit esterazın pozitifliği ile kültürde üreme arasında her zaman korelasyonun olmayabileceği gösterilmiştir (8,12-14). Bu çalışmada komplike olmayan ve komplike (üreter veya böbrek taşı olan) olan hastalarda tam idrar analizi ile idrar kültürünün IYE'de tanısal değer ve etkinliğini araştırmak amaçlanmıştır.

\section{Gereç ve Yöntem}

Tepecik Eğitim Araştırma Hastanesi Üroloji polikliniğine Ocak 2011-Ocak 2013 tarihleri arasında başvuran semptomatik IYE ön tanısı alan, üreter ve/veya böbrek taşı olan 471 hasta incelendi. Tam idrar tahlili (TiT), idrar mikroskopisi ve idrar kültürü beraber istenen ve bilgilerine ulaşılabilen 300 hasta çalışmaya dahil edildi.
Kontrol grubu olarak semptomatik IYE ön tanısı ile kliniğimize başvuran TiT, idrar mikroskopisi, idrar kültürü eş zamanlı istenen 300 hasta çalışmaya dahil edildi. Her üç tetkik beraber istenmeyen, tetkiklerine ulaşılamayan ve antibiyotik tedavisi alan hastalar çalışmadan çıkarıldı. $\mathrm{Bu}$ hastalara öncelikle tam otomatik idrar analizörü (IQ 200 IRIS Diagnostics, ABD) kullanılarak idrarın kimyasal ve mikroskopik analizi yapıldı. Ardından tüm hastalardan idrar kültürü isteği yapıldı. Piyüri ve hematüri için ayrıca idrar örnekleri manuel olarak 3000 devirde 3 dakika santrifüj edildi. Mikroskopta $X 400$ büyütmede her alanda $\geq 5$ beyaz küre piyüri açısından, $\geq 3$ eritrosit hematüri açısından pozitif kabul edildi. İdrar kültüründe $\geq 103$ $\mathrm{cfu} / \mathrm{mL}$ miktarında üreme olması durumunda kültür pozitif olarak kabul edildi. İzole edilen bakteriler konvansiyonel yöntemlerle tanımlandı. Konvansiyonel yöntemle tanımlanamayan izolatlar tam otomatize identifikasyon ve antibiyogram cihazı (VITEK 2 compact Biomerioux, Fransa) ile tanımlandı. Hastalar diabetes mellitus (DM), hipertansiyon (HT), ürolojik girişim öyküsü, üriner sistem tümör varlığı, böbrek taşı, üreter taşı ve daha önce IYE nedeniyle antibiyotik tedavisi alıp almaması yönünden incelendi. Sonuçlar ki-kare test, student t-test ve ROC eğrisi ile SPSS v. 19.0 kullanılarak değerlendirildi. $p$ değerinin $<0.05$ olması istatistiksel olarak anlamlı kabul edildi.

\section{Bulgular}

Üreter ve/veya böbrek taşı bilgisayarlı tomografi ile gösterilmiş olan ve IYE semptomları ile başvuran 300 hasta (Grup 1), bilgisayarlı tüm batın tomografi ile üriner sistem taşı olmadığı gösterilmiş semptomatik IYYE ön tanısı alan 300 hasta (Grup 2) ise kontrol grubu olarak alındı. Grup 1'de ortalama yaş $45.9( \pm 13.9)$ yıl, Grup 2'de ortalama yaş $34.9( \pm 11.7)$ yıl olup Grup 1'de hastaların \%31.7'si kadın, \%68.3'ü erkek; Grup 2'de ise \%44'ü kadın, \%56'sı erkek idi (Tablo-1).

Tablo-1. Gruplara Göre Hastaların Karakteristik Bilgileri.

\begin{tabular}{l|c|c|c}
\hline & $\begin{array}{c}\text { GRUP 1 } \\
\text { n (\%) }\end{array}$ & $\begin{array}{c}\text { GRUP 2 } \\
\text { n (\%) }\end{array}$ & p \\
\hline Kadın & $95(31.7 \%)$ & $132(44 \%)$ & $<0.05$ \\
\hline Erkek & $205(68.3 \%)$ & $168(56 \%)$ & $<0.05$ \\
\hline Tümör öyküsü & $2(0.7 \%)$ & $0(0 \%)$ & $=0.95$ \\
\hline Diabetes mellitus & $22(7.3 \%)$ & $10(3.3 \%)$ & $<0.05$ \\
\hline Hipertansiyon & $34(11.3 \%)$ & $23(7.7 \%)$ & $=0.90$ \\
\hline Üreter taşı varı̆ı̆ & $167(55.7 \%)$ & $0(0 \%)$ & $<0.05$ \\
\hline Komorbit varlığı & $63(21 \%)$ & $40(13.3 \%)$ & $=0.98$ \\
\hline Ürolojik girişim & $3(1 \%)$ & $3(1 \%)$ & \\
\hline $\begin{array}{l}\text { Önceden antibiyotik } \\
\text { alınması }\end{array}$ & $25(8.3 \%)$ & $12(4 \%)$ & $<0.05$ \\
\hline
\end{tabular}

Hastaların 68 (\%11.3)'inde idrar kültüründe üreme saptandı ve en çok üreyen bakteri E.coli (\%77.9) ikinci sıklıkta üreyen bakteri ise Klebsiella spp. (\%10) olduğu 
görüldü. Yüz doksan (\%31.7) hastada böbrek taşı, 110 (\%18.3) hastada ise üreter taşı mevcuttu. Grup 1'deki hastaların 29 (\%9.9)'unda, Grup 2'deki hastaların ise 39 (\%13)'unda idrar kültüründe üreme oldu (Tablo-2).

Tablo-2. Gruplara Göre Tam İdrar Analizi ve İdrar Kültürü Sonuçlarının Dağılımı.

\begin{tabular}{|c|c|c|c|c|c|}
\hline & \multicolumn{2}{|c|}{$\begin{array}{c}\text { GRUP 1 } \\
n(\%)\end{array}$} & \multicolumn{2}{|c|}{$\begin{array}{c}\text { GRUP } 2 \\
\text { n (\%) }\end{array}$} & \multirow[t]{2}{*}{$p$} \\
\hline & $(+)$ & $(-)$ & $(+)$ & $(-)$ & \\
\hline Nitrit & $\begin{array}{c}33 \\
(11 \%)\end{array}$ & $\begin{array}{c}267 \\
(89 \%)\end{array}$ & $\begin{array}{c}57 \\
(19 \%)\end{array}$ & $\begin{array}{c}243 \\
(81 \%)\end{array}$ & 0.85 \\
\hline Eritrosit & $\begin{array}{c}211 \\
(70.3 \%)\end{array}$ & $\begin{array}{c}89 \\
(29.7 \%)\end{array}$ & $\begin{array}{c}122 \\
(40.7 \%)\end{array}$ & $\begin{array}{c}178 \\
(59.3 \%)\end{array}$ & $<0.05$ \\
\hline Lökosit & $\begin{array}{c}171 \\
(57 \%)\end{array}$ & $\begin{array}{c}129 \\
(43 \%)\end{array}$ & $\begin{array}{c}95 \\
(31.7 \%)\end{array}$ & $\begin{array}{c}205 \\
(68.3 \%)\end{array}$ & $<0.05$ \\
\hline Bakteri & $\begin{array}{c}12 \\
(4 \%) \\
\end{array}$ & $\begin{array}{c}142 \\
(47.3 \%) \\
\end{array}$ & $\begin{array}{c}10 \\
(3.3 \%) \\
\end{array}$ & $\begin{array}{c}218 \\
(72.7 \%) \\
\end{array}$ & 0.85 \\
\hline $\begin{array}{l}\text { Kültürde } \\
\text { Üreme }\end{array}$ & $\begin{array}{c}29 \\
(9.7 \%)\end{array}$ & $\begin{array}{c}271 \\
(90.3)\end{array}$ & $\begin{array}{c}39 \\
(13 \%)\end{array}$ & $\begin{array}{c}261 \\
(87 \%)\end{array}$ & 0.08 \\
\hline
\end{tabular}

Tablo-3. Grup 1'deki Hastaların Tam İdrar Analizi Sonuçlarının Değerlendirilmesi.

\begin{tabular}{l|c|c|c|c}
\hline \multicolumn{5}{c}{ GRUP 1 (\%) } \\
\hline & Özgüllük & Duyarlılık & PPD & NPD \\
\hline Lökosit & 48.6 & 41.7 & 8.3 & 1.3 \\
\hline Eritrosit & 28.7 & 8.7 & 11 & 96 \\
\hline Bakteri & 83.8 & 5.8 & 100 & 87.1 \\
\hline Nitrit & 83.3 & 4 & 57 & 93 \\
\hline
\end{tabular}

PPD: Pozitif prediktif değer, NPD: Negatif prediktif değer.

Grup 1 de nitrit, lökosit, eritrosit ve mikroskopide bakteri görülmesinin pozitif prediktif değerleri (PPD) sırasıyla \%57, \%85, \%11, \%75 iken negatif prediktif değerler (NPD) sırasıyla \%93, \%96, \%96, \%90 olarak görüldü (Tablo-3). Grup 2'de ise nitrit, lokösit, eritrosit, mikroskopide bakteri görülmesinin pozitif prediktif değerleri sırasıyla \%21, \%72, \%22, \%100 iken negatif prediktif değerleri sırasıyla \%88.8, \%93.3, \%93.2, \%87.1 olarak tespit edildi (Tablo-4). Her iki grup arasında istatistiksel anlamlılık bulunamadı $(p=0.98)$. Gruplar arasında komorbidite, geçirilmiş operasyon açısından anlamlı bir fark yoktu.

Tablo-4. Grup 2'deki Hastaların Tam İdrar Analizi Sonuçlarının Değerlendirilmesi.

\begin{tabular}{l|c|c|c|c}
\hline \multicolumn{5}{c}{ GRUP 2 (\%) } \\
\hline & Özgüllük & Duyarılık & PPD & NPD \\
\hline Lökosit & 68.3 & 23 & 8.6 & 4.3 \\
\hline Eritrosit & 55.3 & 9 & 22.1 & 93.2 \\
\hline Bakteri & 83.3 & 4,4 & 75 & 90 \\
\hline Nitrit & 72 & 4 & 21 & 88.8 \\
\hline
\end{tabular}

PPD: Pozitif prediktif değer, NPD: Negatif prediktif değer.

\section{Tartışma}

IYE toplumda oldukça sık görülen, ciddi işgücü kaybı ve hayat kalitesinde bozulmaya yol açan bir enfeksiyon hastalığıdır (5). Asemptomatik olabileceği gibi septik şoka kadar gidebilen ölümcül tablolara neden olabilir (1). $\mathrm{Bu}$ nedenle hızlı tanı ve tedavisi önemlidir. Enfeksiyon tanısı için kullanılan yöntemlerin pozitif ve negatif prediktif değerlerinin saptanması, bu enfeksiyonlara tanı konulmasında yol gösterici olmaktadır. Yapılan çalışmalarda, piyüri, proteinüri, nitrit pozitifliği, lökosit esteraz pozitifliği ile idrar kültürü pozitifliklerinin duyarlılık ve özgüllükleri, negatif ve pozitif prediktif değerleri incelenmiş, farklı sonuçlar elde edilmiştir. Tunga ve ark. (13), yaptıkları bir çalışmada idrarda pozitif predikdif değer (PPD) ve negatif predikdif değer (NPD)'leri sırasıyla lökosit esteraz için \%79'a \%61, lökositüri için $\% 81$ 'e $\% 60$, nitrit için $\% 100$ 'e $\% 50$ olarak tespit etmişlerdir(13). Bilgilerimize göre literatürde üriner sistem taşı olan hastaların TiT ve idrar mikroskopisi ile idrar kültürü arasındaki korelasyon değerlendirilmemiştir. Üriner sistem taşı olan hastalarda taşın mukoza irritasyonu ve lokal reaksiyonuna bağlı idrarda eritrosit, lökosit görülebilmektedir. $\mathrm{Bu}$ çalışmada tam idrar analizinde bakılan ve kültür beklenmeden tedavi başlanabilmesine imkan tanıyan eritrosit, lökosit ve nitrit pozitifliğinin, üreter ve böbrek taşı olan hastalarda idrar kültürü sonuçları ile ilişkili olup olmadığı değerlendirilmiştir.

Bu çalışmada Grup 1 ve Grup 2'de sırasıyla piyüri için \%85-\%72, nitrit için \%57-\%21, hematüri için \%11-\%22.1 ve bakteriüri için \%75-\%100 PPD saptanmıştır. Bu testler arasında piyüri olması ve bakteri görülmesi, her iki grup için yüksek PPD ile dikkati çekmektedir. Buna göre tam idrar tetkikinde piyüri varlığı ve idrar mikroskopisinde bakteri görülmesi her iki grup için yüksek intimalle idrar kültüründe üreme olacağını öngörmektedir. Yapılan çalışmalarda nitrit testi duyarlılıkları \%35-45 arası bulunmuştur $(15,16)$. Bu çalışmada ise bu araştırmaların aksine nitrit testinin duyarlılığı \%4, özgüllüğü ise değerlendirilen diğer parametreler içerisinde bakteriüri ile birlikte en yüksek özgüllük değeri olarak bulunmuştur (Grup 1'de \%83.3, Grup 2'de \%72). $\mathrm{Bu}$ sonuca göre, negatif olarak saptandığında kültür sonuçlarının da negatif olacağını en iyi öngörebileceğimiz testin nitrit testi ve bakteriüri olduğu sonucuna varılmıştır. Ayrıca taş hastalarında da bu durumun geçerli olduğu görülmüştür.

$\mathrm{Bu}$ çalışmada bakteriüri yönünden özgüllük oranları Grup 1 ve Grup 2'de sırasıyla \%83.8, \%83.3 olarak tespit edilmiştir. Bakteriüri nitrit ile birlikte duyarılıı̆ı en düşük (\%5.8), özgüllüğü en yüksek olan parametrelerden olmuştur. Literatürde de bu sonuçlara benzer sonuçlar verilmiş olup, bakteriürinin duyarlııı̆ının düşük, özgüllüğünün yüksek olmasının nedeni, idrar kültürün- 
deki koloni sayısının düşük olmasına bağlanmıştır (1719). Bakteriürinin düşük duyarlılık oranı, bu çalışmaya dahil edilen hastalarda bakteriürili olguların az olmasına ve bakteriürisi olmayan hasta sayısının yüksek olmasına bağlı olabilir.

Bu çalışmada Grup 1'deki hastaların \%9.9'unun, Grup 2'deki hastaların ise \%13'ünün idrar kültüründe üreme saptanmıştır ancak bulunan sonuç istatistiksel olarak anlamlı değildir $(p=0,08)$. Enfeksiyona bağlı böbrek taşı olan hastalarda daha yüksek oranda idrar kültüründe üreme saptanabilir (20).

Doğru tanı ve tedavi için günümüzde en iyi tanı testi hala idrar kültürüdür $(21,22)$. İdrar mikroskopisi ve dipstick idrar analizi bir fikir verse de kesin tanıya götürememektedir. Bu sonuçlar tetkikin tek başına değil hastanın semptomları ile beraber değerlendirilerek karar verilmesi gerektiğini göstermektedir. Üriner sistemde taşı olan hastalar bazen IYE semptomları verebilmekte ve idrar analizinde lökosit ve eritrosit görülebilmektedir. Bu çalışmada taşı olan ve taşı olmayan hastalar dipstick idrar analizi, idrar mikroskopisi ve idrar kültürü ile değerlendirilmiş ve her iki grup arasında benzer sonuçlar bulunmuştur. $\mathrm{Bu}$ nedenle üriner sistem taşı olan hastalarda da bu tetkiklerin IYE ön tanısı koymada hasta semptomları ile birlikte değerlendirilerek kullanılabile- ceğini göstermiştir. Ancak dipstick idrar analizi ve idrar mikroskopisi hiçbir zaman idrar kültürünün yerini tutamamaktadır $(14,20)$. Bu çalışmada incelenen parametreler arasında kültürle en yakından ilişkili olan test, dipstick nitrit testi ve bakteriüri olarak belirlenmiştir. Bu çalışmanın üriner sistem taşı olan hastalarda TiT ile idrar kültürünün karşılaştıııldığı ilk çalışma olması açısından önemlidir. Ancak çalışmanın retrospektif olması ve hasta sayısının az olması sınırlayıcı faktör olarak görülmüştür.

\section{Sonuç}

Kliniği IYE ile uyumlu hastalar için bakteriüri, piyüri, hematüri ve nitrit testleri tek başına tanı koymak için yeterli olmayıp özellikle komplike İYE düşünülen hastalar kültür sonuçları ile birlikte değerlendirilmelidir. Üriner sistem taşı olan hastalarda da bu tetkikler aynı şekilde kullanılabilir. Ancak bu hasta grubu komplike IYE olarak değerlendirildiği için mutlaka idrar kültürü yapılmalı ve ampirik olarak başlanan tedavi kültür antibiyogram testleri ile desteklenmelidir. TiT testinde yanlış pozitiflik ya da yanlış negatifliğe, steril piyüri yapan nedenler, kültürde değerlendirme dışı bırakılabilen düşük koloni sayısı (<=102 cfu/ml) ve doğru bir şekilde toplanmamış örnekler neden olabilmektedir.

\section{Kaynaklar}

1. Lane DR, Takhar SS. Diagnosis and management of urinary tract infection and pyelonephritis. Emerg Med Clin North Am $2011 ; 29(3): 539-52$.

2. Stamm WE. Scientific and clinical challenges in the management of urinary tract infections. Am J Med 2002;113(Suppl 1A):1S$4 S$.

3. Koç M, Süleymanlar G. İdrar Yolu Enfeksiyonu, Pyelonefrit ve Reflü Nefropatisi (Çeviri). 7. Baskı. Ankara: MN Medikal \& Nobel; 2008:253-72.

4. Kazancıoğlu R. İdrar Yolu İnfeksiyonları. Nefroloji ve Hipertansiyon El Kitabı (Çeviri). 5. Baskı. Ankara: Güneş Tıp Kitabevi; 2008:153-62.

5. Foxman B. Epidemiology of urinary tract infections: Incidence, morbidity, and economic costs. Am J Med 2002;113(Suppl $1 \mathrm{~A}): 5 \mathrm{~S}-13 \mathrm{~S}$.

6. Mathai $\mathrm{D}$, Jones RN, Pfaller MA. Epidemiology and frequency of resistance among pathogens causing urinary tract infections in 1.510 hospitalized patients: A report from the SENTRY Antimicrobial Surveillance Program (North America). Diagn Microbiol Infect Dis 2001;40(3):129-36.

7. Stamm WE, Hooton TM. Management of urinary tract infections in adults. N Engl J Med 1993;329(18):1328-34.

8. Reller LB, Weinstein MP. Laboratory diagnosis of urinary tract infections in adult patients. Clin Infect Dis 2004;38(8):1150-8.

9. Naber KG, Bishop MC, Bjerklund-Johansen $\mathrm{H}$, et al. EAU guidelines for the management of urinary and male genital tract infections. Urinary Tract Infection (UTI) Working Group of the Health Care Office (HCO) of the European Association of Urology (EAU). (Available from: $h$ ttp://www.uroweb.org 2008.)

10. Brusch JL. Urinary tract infection in Males. (Available from: http://emedicine.medscape.com/article/231574).

11. Tabak F. Enfeksiyon Hastalıkları. 3. Baskı. İstanbul: İstanbul Medikal Yayıncılık; 2009:225-30.

12. Kaçmaz B, Sultan N. Bakteriyüri ve piyüri saptanmasında kullanılan iki yöntemin değerlendirilmesi. İnfeksiyon Dergisi 2003;17(3):337-40

13. Tunga M, Şen TA, Aktepe, OC, Altındiş M. Üriner sistem enfeksiyon şüphesi olan çocuklarda tanımlayıcı laboratuar testlerinin idrar kültür sonuçları ile karşılaştırılması. Türk Ped Arş 2002;37(3):150-5.

14. Van Nostrand JD, Junkins AD, Bartholdi RK. Poor predictive ability of urinalysis and microscopic examination to detect urinary tract infection. Am J Clin Pathol 2000;113(5):709-13.

15. Özer B, Söğüt S, Duran N, Özer C, Kuvandık G, Çetin M. Üriner sistem enfeksiyonlarında laboratuvar testlerinin tanı değerleri. Türk Mikrobiyol Cem Derg 2007;37(2):152-6.

16. Hagay Z, Levy R, Miskin A, Milman D, Sharabi H, Insler V. Uriscreen, a rapid enzymatic urine screening test: Useful predictor of significant bacteriuria in pregnancy. Obstet Gynecol 1996; 87(3):410-3. 
17. Carroll KC, Hale DC, Von Boerum DH, Reich GC, Hamilton LT, Matsen JM. Laboratory evaluation of urinary tract infections in an ambulatory clinic. Am J Clin Pathol 1994;101(1):100-3.

18. Tilton RE, Tilton RC. Automated direct antimicrobial susceptibility testing of microscopically screened urine cultures. J Clin Microbiol 1980;11(2):157-61.

19. Murray PR, Smith TB, McKinney TC. Clinical evaluation of three urine screening tests. J Clin Microbiol 1987; 25(3):467-70.

20. Flannigan R, Choy WH, Chew B, Lange D. Renal struvite stones-pathogenesis, microbiology, and management strategies. Nat Rev Urol 2014;11(6):333-41.

21. Parlaktaş SP, Bulut $\mathrm{Y}$, Özuğurlu AF. İdrar yolu enfeksiyonu tanısında sediment mikroskopisi ve idrar striplerinin kullanımı: Tanısal değerleri ve idrar kültürü ile karşılaştırılması. Fırat Tıp derg 2003;8(4):179-82.

22. Gülcan A, Çelik G, Gülcan E, Cansever Z, Aladağ DM. İdrar yolu enfeksiyonu şüpheli hastalarda tam idrar analizi ve kültür sonuçlarının performans değerlendirmesi. Abant Med J 2012;1(3):129-35. 